\title{
As relações de poder em equipe multiprofissional de Saúde da Família segundo um modelo teórico arendtiano
}

Hadelândia Milon de Oliveira ${ }^{1}$

Rodrigo Otávio Moretti-Pires ${ }^{2}$

Rosana Cristina Pereira Parente ${ }^{3}$

OLIVEIRA, H.M.; MORETTI-PIRES, R.O.; PARENTE, R.C.P. Power relations in a Family Health multidisciplinary team according to an Arendtian theoretical model. Interface Comunic., Saude, Educ., v.15, n.37, p.539-50, abr./jun. 2011.

The Family Health Strategy (FHS) is based on teamwork and demands changes in the work process of the Health Care units, breaking the traditional model centralized on the physician's role. The present study aims to propose a theoretical model to assess power relations within the multidisciplinary team, grounded on Hannah Arendt's work. Based on an analysis of legal documents of the FHS and on Arendt's assumptions, a theoretical model for FHS evaluation was set up using a qualitative and hermeneutic-dialectic approach. In order to test the model, focus groups with health care teams and individual interviews were conducted in the municipality of Manacapuru - State of Amazonas (Northern Brazil). The results show that each professional performs his/her role in isolation, without sharing with others. The local management policy limits the collective work and does not use leadership principles; it is characterized as tyranny in Arendt's perspective, which brings discredit to the FHS.

Keywords: Power. Family health. Patient care team. Focus group.
A Estratégia Saúde da Família (ESF) está fundamentada no trabalho em equipe, exigindo mudanças no processo de trabalho das Unidades de Saúde, distanciando-se do modelo centralizado na figura do médico. Este trabalho objetiva propor um modelo teórico de avaliação da relação de poder na equipe multiprofissional, com base nos trabalhos de Hannah Arendt. Baseando-se em análise de documentos legais da ESF e dos pressupostos arenditianos, estabeleceuse um modelo teórico para avaliação da ESF, utilizando-se a abordagem qualitativa com enfoque hermenêutico-dialético. Para testar o modelo, aplicaram-se grupos focais com as equipes de saúde e entrevistas individuais no município de Manacapuru - interior do Estado do Amazonas. Os resultados mostram que cada profissional exerce sua função de forma isolada, não compartilhada; a política da gestão municipal é limitadora do trabalho coletivo, não governando com liderança, mas se configurando como tirania na perspectiva arendtiana, trazendo descrédito à ESF.

Palavras-chave: Poder. Saúde da família. Equipe de assistência ao paciente. Grupo focal.
1 Escola de Enfermagem de Manaus, Universidade Federal do Amazonas. R. Terezina, 495 Adrianópolis. Manaus, AM, Brasil. 69.060-000. hmilon@ufam.edu.br 2 Universidade Federal de Santa Catarina.

${ }^{3}$ Universidade Federal do Amazonas. 


\section{Introdução}

A Estratégia de Saúde da Família (ESF) foi adotada como importante mecanismo para a transformação do modelo assistencial brasileiro. Pautada nas diretrizes de integralidade, equidade e universalidade, a ESF propõe nova dinâmica para a organização dos serviços de saúde (Trad, Bastos, 1998). Fundamenta-se na lógica de adscrição de clientela, no trabalho em equipe multiprofissional e na participação da população - em uma lógica que rompe com o modelo centrado no profissional e prima pela aproximação da vida da comunidade. Seu processo de trabalho possibilita o compromisso e a corresponsabilidade da equipe e usuário, tanto quanto a articulação entre os diversos saberes das corporações profissionais que compõem este modelo assistencial (Brasil, 2001). A adoção deste modelo assistencial no Brasil foi impelida com vistas à efetividade do Sistema Único de Saúde (SUS) de fato, muito mais do que uma questão de fundo ideológico, sendo necessária a mudança no processo de trabalho das Unidades Básicas de Saúde.

A implantação da ESF vem contribuindo para a consolidação de uma gestão descentralizada e participativa no SUS, configurando-se como uma política de saúde para maior garantia dos direitos do usuário. A reorientação do Programa de Saúde da Família como estratégia de reorganização da Atenção Primária pode ser considerada como um dos mais importantes avanços ideológicos e práticos em termos de gestão do SUS, uma vez que não se trata apenas de ampliar o acesso e a abrangência geográfica dos serviços, mas, também, sua adoção de práticas da atenção sob novas bases epistemológicas do fazer/ cuidar em saúde, com substituição do modelo então vigente, levando a saúde para mais perto das famílias e melhorando-se a qualidade de vida dos cidadãos brasileiros (Brasil, 2001).

O recurso humano que atua na ESF é organizado a partir do trabalho em equipe multiprofissional, composta, minimamente, por: um médico generalista, um enfermeiro, um auxiliar de Enfermagem, quatro a seis agentes comunitários de saúde, um odontólogo e um auxiliar em saúde bucal e/ou um técnico em saúde bucal. Os profissionais desta última área foram incluídos na ESF a partir do ano 2000.

Além das atribuições específicas do saber corporativo, os profissionais da equipe têm diversas responsabilidades comuns, tais como: conhecer a realidade das famílias pelas quais são responsáveis; identificar seus problemas de saúde e situações de risco mais comuns; e construir, conjuntamente, um planejamento para enfrentamento dos mesmos, discutindo com a comunidade conceitos de cidadania, de direitos à saúde e suas bases legais (Brasil, 2006a).

Nesta perspectiva, a ESF tenta superar o modelo hegemônico centrado na figura do médico e propõe uma nova forma de assistir à população, colocando como ponto-chave o trabalho multiprofissional. Esta abordagem representa um processo de relações a serem pensadas pelos próprios trabalhadores e que possui múltiplas possibilidades de significados ao articular os diversos saberes da equipe.

A despeito das atribuições específicas de cada categoria profissional, a equipe deve desenvolver, de maneira conjunta e integrada, ações preventivas e de promoção da qualidade de vida na comunidade, além de intervenções para recuperação e reabilitação da saúde, tanto na unidade de saúde quanto nos demais espaços comunitários - externos a esta -, associando a atuação clínica e técnica às práticas de saúde na coletividade (Valentim, Kruel, 2007).

As características do trabalho de Saúde em equipe fundamentam-se nas relações interpessoais e, como tal, geram relações de poder (Fortuna et al., 2005). Acrescida a estas características, a organização coletiva do trabalho institucionalizada promove relações de desejos, interesses e conflitos decorrentes. Em ambas as perspectivas, existem pessoas que "podem mais" e as que "podem menos" (Fortuna et al., 2005, p.265). Particularmente nas equipes de Saúde, há um terceiro elemento que trata das competências, poderes e status de cada corporação de trabalho. "Trabalhar em equipe requer rever poderes, desocultar os poderes, olhar se sua disputa não está incoerente com a direcionalidade do trabalho: no caso do PSF, a democratização e a construção de trabalhadores e usuários cidadãos" (Fortuna et al., 2005, p.265).

A característica relacional do poder nos grupos é uma das importantes contribuições do pensamento de Hannah Arendt ao conhecimento do século XX. De reconhecimento internacional, esta teórica é conhecida como a pensadora da liberdade. Seus trabalhos teóricos fundamentaram-se nas grandes transformações do poder político durante sua existência. Por influência de sua condição 
de judia alemã, estudou a formação dos regimes autoritários instalados nesse período - o nazismo e o comunismo - e defendeu os direitos individuais e a família, contra as "sociedades de massas" e os crimes contra a pessoa. Sua obra é fundamental para se entender e refletir sobre os tempos atuais e as relações de poder que estão estabelecidas e em constante transformação. Hanna Arendt (2008a) defendia que compreender significa enfrentar sem preconceitos a realidade e resistir a ela.

Um importante conceito arendtiano refere-se ao "espaço de aparência", categoria na interface entre o que se propõe e o agir em si. Independente das orientações formais que impelem os seres humanos a estarem uns com os outros, é um conceito que se refere à forma coletiva da interação humana. O espaço de aparência "[...] passa a existir sempre que os homens se reúnem na modalidade do discurso e da ação, e, portanto precede toda e qualquer constituição formal e as várias formas de governo, isto é, as várias formas possíveis de organização da esfera pública" (Arendt, 2008b, p.211).

O "espaço de aparência" refere-se ao comportamento das pessoas em suas posições/ representações em um grupo social de convivência, podendo um indivíduo exercer o poder ou ser influenciado pelo poder de outro. E esse espaço é relacional e só existe quando os homens se reúnem, não sendo durável ou permanente. O espaço de aparência surge no convívio entre os homens.

Hannah Arendt defende que o poder só se torna legítimo na utilidade coletiva efetiva, de forma que o poder genuíno se caracteriza pelas intenções explícitas coerentes com as práticas em si, de maneira indissociável. "O poder só é efetivado enquanto a palavra e o ato não se divorciam, quando as palavras não são vazias e os atos não são brutais, quando as palavras não são empregadas para violar ou destruir, mas para criar relações e novas realidades" (Arendt, 2008b, p.212).

Com base nos pressupostos arendtianos, o presente artigo tem o objetivo de avaliar as relações de poder, conflitos e barreiras na equipe multiprofissional da ESF de um município do interior do Estado do Amazonas.

\section{Percurso metodológico e modelo teórico}

Trata-se de uma pesquisa avaliativa, fundamentada nos conceitos sobre relações de poder oriundos dos pressupostos de Hannah Arendt (2009, 2008a, 2008b), assim como nas bases documentais sobre ESF no Brasil (Brasil, 2006a, 2006b, 2001). Foram analisados os conceitos-chave sobre trabalho em equipe, conforme as normas estabelecidas para o funcionamento da ESF, à luz dos referidos pressupostos arendtianos, estabelecendo-se um Modelo Teórico e Matriz conceitual, seguindo as definições de Hartz (2002) para o tipo de pesquisa empreendida.

A opção pela abordagem qualitativa mostrou-se mais adequada para o fenômeno investigado, tendo em vista a necessidade de se imergir nas singularidades e a natureza do objeto "relações de poder" na "equipe multiprofissional de Saúde da Família" (Minayo, 2006; Minayo, Assis, Souza, 2005).

A coleta de dados empíricos foi empreendida em Manacapuru (AM), distante $70 \mathrm{~km}$ de Manaus. Este é um dos únicos municípios em que existe acesso geográfico terrestre à capital. O universo de investigação foram dez equipes da ESF que atuam na zona urbana. Existem mais doze equipes na rede pública de Saúde, mas que atuam na zona rural e que, por esta característica, têm características diferenciadas em relação às primeiras.

Em termos instrumentais, as técnicas de entrevista individual (EI) e de grupo focal (GF) foram utilizadas na coleta de informações (Minayo, 2002; Morgan, 1997). Além do moderador, houve um segundo pesquisador no papel de observador. Ambos se reuniram para discutir as impressões ao término de cada grupo focal, que tiveram duração média de uma hora e meia. As questões norteadoras referiram-se: aos conceitos sobre o que é equipe, às relações interpessoais/intersubjetivas e problemas que surgem durante o processo de trabalho nesta forma de organização do serviço, à forma como é organizado o trabalho na ESF, à atuação do profissional nos diversos níveis de atenção à Saúde, e ao trabalho em equipe multiprofissional como construção coletiva. Para as El, foram entrevistados todos os integrantes dos GF.

O modelo foi aplicado ao material empírico de quatro GF, nos quais participaram todos os membros das equipes investigadas e das $52 \mathrm{El}$. O indicador para a amostragem foi a saturação das informações, 
descrita como o aparecimento de reincidência de perspectivas sobre o fenômeno, indicando que o acréscimo de sujeitos não implicaria necessariamente novidades acerca do mesmo (Minayo, Assis, Souza, 2005). Esta forma de amostragem também é conceituada como amostra teórica (Minayo, Assis, Souza, 2005).

O uso simultâneo de ambas as técnicas de coleta de informações permite que o pesquisador confirme ou não as impressões que emergem em cada uma, possibilitando maior confiança na interpretação dos dados (Minayo, 2006; Morgan, 1997).

A análise das informações fundamentou-se em uma postura hermenêutica-dialética (Minayo, 2002), perspectiva adotada pela reflexão interpretativa que se funda na práxis e na busca pela compreensão atrelada à análise crítica da realidade, processualmente seguindo as etapas de confrontação, convergências e divergências das categorias (Campos, Rodrigues, Moretti-Pires, 2011; Minayo, Assis, Souza, 2005).

Inicialmente, realizou-se a leitura exaustiva para apropriação de conteúdo, seguida de redução do material empírico e análise por confrontação com o modelo teórico/matriz estabelecido, conforme descrito anteriormente. Na aplicação do modelo de tratamento, foram observados os conteúdos coerentes, singulares ou contraditórios - o que caracterizou a postura hermenêutico-dialética em termos processuais (Campos, Rodrigues, Moretti-Pires, 2011; Minayo, Assis, Souza, 2005). O material utilizado resultou de gravações sonoras, transcritas na íntegra.

Os entrevistados foram recrutados individualmente, por meio do contato de um dos pesquisadores com as unidades de Saúde. Todos os entrevistados participaram após registro formal no termo de consentimento livre e esclarecido, em duas vias. Ressalta-se que foram respeitadas as normas de pesquisa envolvendo seres humanos, com aprovação do Comitê de Ética em Pesquisa da Universidade Federal de Santa Catarina - Projeto "Saúde da Família no interior do Estado do Amazonas e a operacionalização dos princípios do SUS", fomentado pelo Conselho Nacional de Desenvolvimento Científico e Tecnológico (Processo CNPq 470165/2008-1).

\section{Modelo teórico empregado}

Para Hannah Arendt, a vida coletiva pode ser observada sob duas perspectivas: o discurso e a ação. $O$ primeiro refere-se às intenções, às ideologias, às leis e ao discurso que formalmente caracteriza determinado grupo, seus processos normativos e a justificativa oficial para existência social do mesmo. A segunda refere-se à vida vivida propriamente dita, que tem dinâmica própria e acontece independente do discurso e da ideologia oficial que sustenta o grupo. É na ação que os homens se veem e estabelecem as relações de poder, caracterizando o "espaço de aparência" como não permanente e dinâmico (Arendt, 2008b, p.211).

Na perspectiva da articulação entre o discurso oficial sobre a ESF e as decorrências para a ação coerente com o mesmo, construiu-se o modelo teórico representado pelo diagrama abaixo (Figura 1).

A figura diagramática apresentada agrega os conceitos que se seguem. 


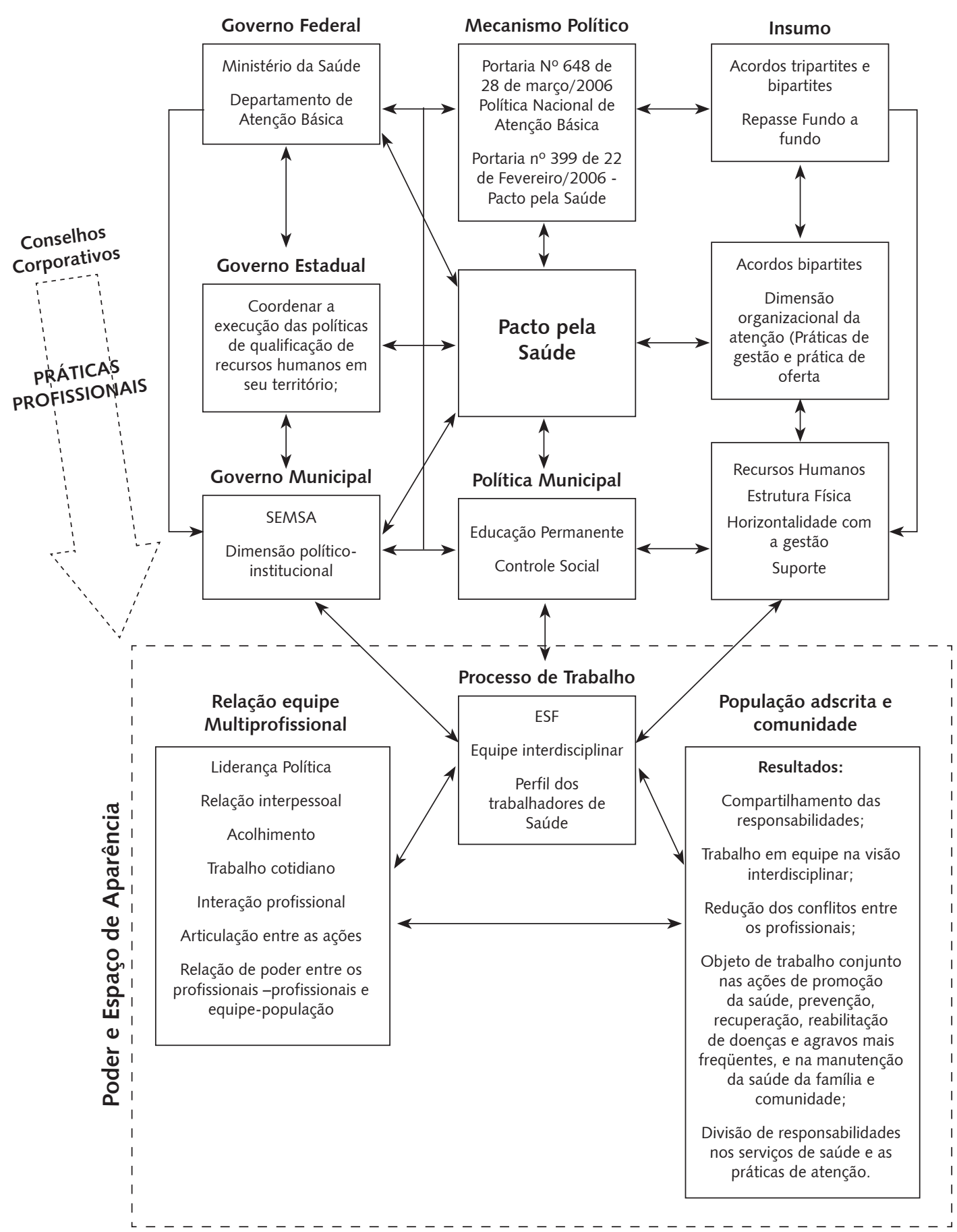

Figura 1. Modelo teórico-conceitual referente às relações de poder na equipe multiprofissional da ESF 


\section{Do discurso - o conteúdo normativo}

O Ministério da Saúde divulgou, em 2006, o Pacto pela Saúde 2006 (Brasil, 2006b), como estratégia para fortalecimento da Atenção Primária e descentralização das responsabilidades nas três esferas. Há uma importante ênfase nas necessidades de saúde da população por meio da priorização de três perspectivas: o Pacto pela vida, o Pacto em Defesa do SUS e o Pacto de Gestão do SUS. Trata-se de uma importante iniciativa, promovendo inovações nos processos e instrumentos de gestão, objetivando alcançar maior efetividade, eficiência e qualidade das respostas aos usuários. Ao mesmo tempo, são redefinidas as responsabilidades coletivas de cada esfera de governo, tomando-se, como indicadores, os resultados sanitários em função das necessidades de saúde da população e equidade social.

Outro discurso importante é o da Política Nacional de Atenção Básica (Brasil, 2006a), que define o funcionamento da ESF e a declara como prioridade para a organização do sistema público de acordo com os preceitos do SUS. Dentre os seus fundamentos, destacam o desenvolvimento de relações de vínculo e de responsabilização entre as equipes e população adscrita, preconizando a continuidade das ações de saúde e a longitudinalidade do cuidado.

Os Governos Municipais responsabilizam-se pela estrutura física adequada para a execução das ações de promoção de saúde, assim como pelo estabelecimento de política para a contratação de recursos humanos, bem como a qualificação e capacitação dos mesmos. O planejamento dessas ações e a execução de educação permanente também são responsabilidade da gestão municipal, que deve dar suporte e estabelecer horizontalidade junto aos profissionais. As diretrizes orientam que se estimule a participação popular e o controle social, tanto quanto a viabilização de parcerias com organizações governamentais, não governamentais e com o setor privado, para o fortalecimento da Atenção Básica no âmbito do seu território.

\section{Da ação - poder e espaço de aparência}

Dos princípios norteadores da ESF, destaca-se a potencialidade para que seja um espaço de construção de cidadania. O processo de prestação de serviços em saúde da família tem um conteúdo fundamentado na interdisciplinaridade e no trabalho em equipe, integrando diferentes formações/ áreas técnico-profissionais. Há valorização dos diversos saberes e práticas na perspectiva de uma abordagem integral e resolutiva, possibilitando a criação de vínculos de confiança com ética, compromisso e respeito. Preconiza-se a promoção e o estímulo à participação da comunidade no controle social, no planejamento, na execução e na avaliação das ações. Também há ênfase no acolhimento, na participação de todos os integrantes das equipes no planejamento e na avaliação das ações, tanto quanto no apoio a estratégias de fortalecimento da gestão local.

Como resultado da implementação desses conceitos na prática, espera-se o compartilhamento das responsabilidades no trabalho em equipe, com abordagem interdisciplinar, ocasionando a redução dos conflitos entre os profissionais. A liderança emerge do encontro entre os diversos membros da equipe, cuja divisão de responsabilidades, nos serviços de saúde e nas práticas de atenção, manifestarse-á enquanto ação no trabalho conjunto para: a promoção da saúde da família e comunidade, a prevenção, a recuperação, a reabilitação de doenças e agravos mais frequentes.

\section{Resultados e discussão}

A Política Nacional de Atenção Básica preconiza que o processo de trabalho em saúde crie relações de vínculo/responsabilização entre as equipes e população adscrita, garantindo a continuidade das ações de saúde e a longitudinalidade do cuidado. Porém, percebeu-se certo distanciamento e falta de articulação entre as equipes de saúde investigadas e a população, no planejamento e construção de estratégias nas ações de saúde. O cuidado dos usuários é descontínuo entre as diversas profissões, emergindo problemas no trabalho integrado e em equipe. 
O controle social é pouco exercido, não havendo estímulo dos gestores para que a participação social da população ocorra de acordo com o preconizado (Crevelim, Peduzzi, 2005). Não há articulação destinada ao fortalecimento da Atenção Básica no âmbito do seu território, com a viabilização de parcerias com organizações governamentais, não governamentais e com o setor privado.

Neste contexto é importante ressaltar que, para Hannah Arendt, poder "corresponde à habilidade humana não apenas para agir, mas também para agir em concreto. [...] nunca é propriedade de um indivíduo; pertence a um grupo e permanece em existência apenas na medida em que o grupo se conserva unido" (Arendt, 2009, p.36). Esta característica humana refere-se à relação de consentir e de ser consentido, já que "o consentimento implica o reconhecimento de que nenhum homem pode agir sozinho [...]" (Arendt, 2008a, p.336).

Estas concepções refletem diretamente o fundamento e a prática da liderança política, assim como das relações de poder entre os gestores, as equipes de ESF e a população. Com base no modelo teórico proposto, indica-se a existência de fragilidades na coerência entre o discurso e a ação.

Foram encontrados problemas com as condições físicas das Unidades de Saúde, que não dispõem de estrutura física adequada para execução das ações de promoção de Saúde. Em alguns casos, até três equipes da ESF atuam na mesma Unidade, sem salas adequadas para recepção. Há inadequação dos consultórios médicos, de enfermagem e odontológicos. Os cuidados odontológicos estavam suspensos, por falta de equipamentos e insumos clínicos.

As atividades de Saúde da Família são desenvolvidas em conjunto com o modelo de Unidade Básica de Saúde tradicional, sobrecarregando os profissionais de saúde. Esta sobrecarga refere-se ao desempenho das atividades previstas ao modelo do PSF - tais como as visitas domiciliares -, além daquelas características do modelo curativo-assistencial tradicional.

São grandes as implicações desta realidade frente ao que é idealizado no âmbito do trabalho da ESF. O discurso e a ação são antagônicos, uma vez que há carência em termos de compartilhamento de responsabilidades, trabalho interdisciplinar efetivo e desenvolvimento de projetos terapêuticos conjuntos.

Propiciam-se, então, problemas nos processos de trabalho e divisão de atribuições nos serviços, propiciando a existência de conflitos. Este panorama, distante do que é minimamente proposto no modelo da ESF, interferirá diretamente nas relações de poder e acirramento de disputas entre os profissionais e a comunidade.

Não foi identificada qualquer política de recursos humanos, no sentido de contratação bem como de qualificação dos profissionais, tendo em vista o silêncio com relação a planejamento e execução de educação permanente, sobretudo na perspectiva dessas iniciativas construídas junto aos diversos profissionais e destes para com a gestão.

Em relação à educação permanente, quando há, ocorre somente para os ACS. Nunca é realizada em equipe, havendo queixas sobre iniciativas advindas dos médicos e dos enfermeiros. Há silêncio sobre esta temática por parte dos odontólogos. Este se sente excluído e esquecido. Uma decorrência refere-se à falta de preparo dos profissionais para o trabalho na visão multiprofissional e na promoção de saúde através dos vários saberes. Este contexto refere-se a uma das fragilidades existentes entre o discurso que fundamenta a ESF e a ação que se dá na vida vivida, em termos arendtianos.

Os profissionais são contratados através de indicação política, não havendo processos seletivos ou mesmo concursos públicos. Todos os contratos são temporários, gerando desconforto e constante insegurança para esses profissionais, já que existem pressões políticas que os fazem se submeterem a trabalhar em condições mínimas de trabalho. Este tipo de trabalho pode ser caracterizado como vínculo precário, sendo eminentes os problemas ocasionados em termos das relações humanas, conforme o modelo teórico apresentado.

O poder é exercido verticalmente, dos gestores para os profissionais, gerando tensão nas relações interpessoais e contribuindo para a falta de confiança entre os gestores e os profissionais quadro dicotômico ao considerado positivo nos pressupostos arendtianos, tal como apresentado no modelo teórico. 
Esta forma de pressão política fragiliza a efetividade da ESF. Alguns profissionais expressaram que o seu contrato tem a duração de quatro anos - tempo de um mandato - sendo incerto se haverá renovação na próxima gestão. Estas questões concernentes à política de recursos humanos promovem a descontinuação das ações e garantem a conformidade das ações de acordo com os interesses políticos da gestão vigente.

A tirania é descrita por Arendt como uma relação humana que se fundamenta "[...] no isolamento - o isolamento do tirano em relação aos súditos, e dos súditos entre si através do medo e da suspeita generalizada" (Arendt, 2008b, p.214). Sua violência se caracteriza por contradizer "a condição humana de pluralidade, o fato de que os homens agem e falam em conjunto, que é a condição de todas as formas de organização política" (Arendt, 2008b, p.215), e que "... embora a tirania se caracterize sempre pela impotência dos seus súditos, privados da capacidade humana de agir e falar em conjunto, não é necessariamente caracterizado pela fraqueza e esteridade" (Arendt, 2008b, p.214-5).

De maneira contundente, Hannah Arendt afirma que "[...] a tirania é incapaz de engendrar suficiente poder para permanecer no espaço de aparência, que é a esfera pública; ao contrário tão logo passa a existir gera a semente de sua própria destruição" (Arendt, 2008b, p.215).

Como reflexo do contexto apresentado, a ESF apresenta-se distante do trabalho integrado, horizontalizado e consonante aos seus preceitos fundamentais, uma vez que a relação humana e as relações de poder advindas desta são sustentáculos para o bom funcionamento, conforme o modelo teórico desenvolvido no presente trabalho.

Com relação à ação da ESF em Manacapuru, pouco se percebe sobre sua legitimidade como um espaço para a construção da cidadania. Os profissionais não desenvolvem ações de trabalho em equipe, desempenhando apenas suas competências profissionais clássicas. Um emblema deste fenômeno é a quase inexistência de articulação dos demais profissionais com a Odontologia. Este panorama é distante da relação de poder genuína preconizada por Arendt, assim como para a proposta de trabalho na ESF.

No município investigado, o enfermeiro exerce a função de gerente da unidade, sobreposta às ações de assistência, além das responsabilidades específicas junto a outros programas, exercendo três funções. Há, portanto, acúmulo de atividades administrativas, sendo uma imposição dos gestores locais, e não uma liderança genuína nos termos arendtianos. Em alguns casos, não são reconhecidos como líderes pelos demais profissionais, sobretudo do nível Superior, uma vez que não são escolhidos entre os membros da equipe, mas, sim, indicados, em um fluxo verticalizado e que gera inúmeros conflitos.

Por estas características da gestão local, as decisões são tomadas unilateralmente, com pouco envolvimento dos demais integrantes da equipe no planejamento e tomadas de decisões. O poder não ocorre de forma compartilhada, com corresponsabilidade nas ações de promoção de saúde, interferindo negativamente na criação de vínculos de confiança com ética, compromisso e respeito, conforme o preconizado dentro do modelo teórico arendtiano proposto no presente trabalho.

A relação de poder com a população também é verticalizada. Os profissionais não estimulam a participação da comunidade no controle social, no planejamento, na execução e na avaliação das ações. Percebem o usuário como alguém que precisa de conhecimento, transferindo a culpa de seus problemas de saúde aos mesmos. Por outro lado, os usuários, quando não desejam ser atendidos por determinado profissional - principalmente o ACS - e têm influência política no município, fazem denúncia, verdadeiras ou não, provocando a demissão desse profissional. O mesmo usuário acaba por indicar outro profissional para substituí-lo, nem sempre sendo o profissional ouvido antes da exoneração. Essa situação gera tensões nas relações profissional/usuário, agudizando o quadro de relações de poder prejudiciais e não construtivas.

Para Arendt, a coerência entre a ideologia e a ação é fundamental. A desarmonia entre estas promove a violência. "O poder só é efetivado enquanto a palavra e o ato não se divorciam, quando as palavras não são vazias e os atos não são brutais, quando as palavras não são empregadas para violar e destruir, mas para criar relações e novas realidades" (Arendt, 2008b, p.212). O modelo teórico empregado preconiza o exercício do acolhimento, por meio de estratégia de participação da equipe no planejamento e avaliação da ação, porém isso não foi percebido empiricamente. Contrariamente, há relações de verticalidade entre os atores implicados na ESF. 
O conceito de "espaço de aparência" mostrou-se pertinente ao processo de trabalho da equipe interdisciplinar, sofrendo influência: da liderança política, da relação interpessoal, do acolhimento, do trabalho cotidiano, da interação profissional, das articulações entre as ações e das relações de poder entre os profissionais/profissionais e equipe/população. Para Arendt, " [...] a esfera política resulta diretamente da ação em conjunto, da co-participação de palavras e atos. A ação, portanto, não apenas mantém a mais íntima relação com o lado público do mundo, comum a todos nós, mas é a única atividade que o constitui" (Arendt, 2008b, p.210).

Machado (2005) aponta a existência de fragilidades no trabalho em equipe, que significa interação entre os diversos profissionais - um dos pilares deste modelo de atenção, orientado à integralidade nos cuidados de saúde pautada na relação entre a complementaridade de trabalhos e a interação dos profissionais (Araújo, Rocha, 2007; Chaves, 2003).

Nesta perspectiva, ao adotar a ESF o enfoque no atendimento integral, humano, complexo e multidimensional, há necessidade de profissionais que articulem sua atuação profissional de maneira intersetorial com a realidade adscrita (Moretti-Pires, 2009).

As relações de poder demonstradas na aplicação do Modelo Teórico arendtiano proposto apontam para a desconsideração de conhecimentos próprios dos usuários, discurso antagônico à relação horizontal na ESF. Uma explicação a esta manifestação pode ser a formação dos profissionais de saúde ainda se orientar por conceitos antropológicos hegemônicos na década de 1960, em que a cultura do outro - no caso, o usuário - é tomada como um saber 'exótico' ou primitivo, com supervalorização do conhecimento biomédico (Boehs et al., 2007).

Existem dificuldades, por parte dos profissionais, de ouvirem demandas dos usuários e, por consequência, tratá-los como sujeitos, permanecendo o enfoque do cuidado centrado nos protocolos de saúde, e não no usuário (Silvia, Trad, 2005; Pires, 2005). Estes achados implicam a discussão da categoria 'cuidado', que tem sido re-significada na literatura atual em direção às dimensões sociais e políticas, mediação entre ajuda e poder de ajudar, implicando a questão de autonomia dos usuários.

$\mathrm{Na}$ ESF, a produção de serviços de saúde não deveria se distanciar da noção de historicidade do usuário como sujeito, de conhecimentos próprios e tão importantes quanto os saberes dos profissionais de saúde. Esta abordagem está diretamente implicada nas relações de poder, estabelecidas tanto no interior da equipe como em sua relação com os usuários, conforme aplicação dos pressupostos arendtianos já expostos.

Com relação ao trabalho em equipe, há cristalização de problemas corporativos clássicos em Saúde no contexto investigado. A Enfermagem aponta para constante luta por valorização e para se firmar perante as demais profissões; o médico se concebe como figura central do trabalho nos serviços; enquanto fica patente a pouca relação dos odontólogos com a equipe, a exemplo de sua conceituação de que equipe é o agregar dos diversos profissionais em um mesmo local.

Estas perspectivas são contraditórias com os princípios do trabalho multiprofissional efetivo. São características imprescindíveis deste: a interdisciplinaridade e visão crítico-social, a expertise técnica confluente com relações intersubjetivas dialógicas e respeitosas para com o outro, em que um profissional de saúde deve tanto se articular com os demais como promover articulação intersetorial (Moretti-Pires, 2009; Figueiredo, 2006; Schraiber et al., 1999). Trata-se de um padrão arraigado no processo de trabalho nas equipes investigadas, podendo estar implicado no silêncio/resistência destes profissionais em discutir o trabalho pela lógica da ESF (Moretti-Pires, 2009).

De maneira dicotômica com o modelo aredtiano proposto, a postura autoritária permeou os discursos, não apenas com relação ao usuário, mas também para com a equipe, na qual o enfermeiro percebe-se como líder da gestão, o médico percebe centralidade e status superior aos demais, por julgar possuir maiores conhecimentos técnicos em saúde. Houve certo silêncio nos discursos sobre a relação da Odontologia com as demais profissões do trabalho em equipe. Estas perspectivas implicam ausência na construção de um projeto coletivo na ESF, que depende não apenas das formas concretas de organização do trabalho, mas, também, da distribuição de poder na equipe, em conformidade com os pressupostos arendtianos e o preconizado para o trabalho na ESF, conforme modelo teórico do presente artigo. 


\section{Considerações finais}

No que concerne à situação da ESF no município investigado, fundamentando a análise no modelo teórico proposto a partir dos trabalhos de Hannah Arendt, avalia-se que existe desacordo entre o discurso e a ação, apesar de mecanismos tais como a implementação do Pacto de Saúde. Percebeuse a ausência de estratégias de trabalho consolidadas, com ênfase nas necessidades de saúde da população, visando alcançar maior efetividade, eficiência e qualidade de suas respostas, visualizadas nos resultados sanitários em função das necessidades de saúde da população e na busca da equidade social, preconizados pelo pacto.

Os resultados encontrados trazem a percepção de ausência de trabalho em equipe genuíno, reflexo de um contexto em que cada profissional exerce sua função de forma isolada, não compartilhada, o que contribui para o estabelecimento de conflitos de poder entre os diversos atores. O poder exercido pela gestão imobiliza as ações de trabalho coletivo, com fragmentação na organização do processo de trabalho, manutenção de antigas disputas corporativas refletidas nas relações de poder entre os profissionais, assim como entre a equipe e a população. Como consequência, há descrença na ESF como idealizada. Em termos arendtianos, há divergência entre o discurso idealizado para o SUS operacionalizado no campo empírico investigado pela ESF - e a ação.

Hannah Arendt conceitua a ação como os atos praticados de maneira indissociável das palavras ou discurso, pois quando ocorre dissociação há enfraquecimento. Este enfraquecimento é indesejável, uma vez que, como diz Arendt: "É o poder que mantém a existência da esfera pública, o espaço potencial da aparência entre homens que agem e falam" (Arendt, 2008b, p.212). Esta potencialidade pode ser efetivada, e não a materializada.

O modelo teórico com base nos pressupostos arendtianos pode orientar a avaliação da relação de poder na equipe multiprofissional da ESF, contribuindo para a construção de estratégias que venham gerar subsídios para identificar aquilo que está sendo alcançado e o que interfere nas relações humanas que permeiam o trabalho em equipe neste modelo assistencial.

\section{Colaboradores}

Os autores trabalharam juntos em todas as etapas de produção do manuscrito.

\section{Referências}

ARAUJO, M.B.S.; ROCHA, P.M. Trabalho em equipe: um desafio para a consolidação da estratégia de saúde da família. Cienc. Saude Colet., v.12, n.2, p. 455-64, 2007.

ARENDT, H. Sobre a violência. Rio de Janeiro: Civilização Brasileira, 2009.

A vida do espírito. Rio de Janeiro: Civilização Brasileira, 2008a.

A condição humana. Rio de Janeiro: Forense Universidade, 2008b.

BOEHS, A.E. et al. A interface necessária entre a enfermagem, educação em saúde e o conceito de cultura. Texto Context Enferm., v.16, n.2, p.307-14, 2007.

BRASIL. Ministério da Saúde. Secretaria de Atenção à Saúde. Departamento de Atenção Básica. Política Nacional de Atenção Básica. Brasília: MS, 2006a.

. Ministério da Saúde. Secretaria de Atenção à Saúde. Departamento de Atenção Básica. Pacto pela Saúde. Brasília: MS, 2006b.

. Ministério da Saúde. Secretária de Políticas Públicas. Guia Prático do Programa de Saúde da Família. Brasília: MS, 2001. 
CAMPOS, D.A; RODRIGUES, J.; MORETTI-PIRES, R.O. Pesquisa qualitativa em saúde coletiva como instrumento de transformação social: uma proposta fundamentada no pensamento hermenêutico-dialético. Saude Transform. Soc., v.1, n.3, 2011. (No prelo).

CHAVES, M. Complexidade e transdisciplinaridade: uma abordagem multidimensional do setor saúde. São Paulo: Rede CEDROS, 2003.

CREVELIM, M.A.; PEDUZZI, M. Participação da comunidade na equipe de saúde da família: é possível estabelecer um projeto comum entre trabalhadores e usuários? Cienc. Saude Colet., v.10, n.2, p.323-31, 2005.

FIGUEIREDO, J.S. Desafios e perspectivas em atividades educativas de promoção de saúde de um grupo de portadores de hipertensão arterial, sob o paradigma da interdisciplinaridade. 2006. Tese (Doutorado) - Escola de Enfermagem de Ribeirão Preto, Universidade de São Paulo, Ribeirão Preto. 2006.

FORTUNA, C.M. et al. O trabalho de equipe no programa de saúde da família: reflexões a partir de conceitos do processo grupal e de grupos operativos. Rev. Latino-Am. Enferm., v.13, n.2, p.262-68, 2005.

HARTZ, Z.M.A. Avaliação em saúde: dos modelos conceituais à prática na análise da implantação de programas. Rio de Janeiro: Fiocruz/Abarsco, 2002.

MACHADO, M.H. Trabalhadores da saúde e sua trajetória na reforma sanitária. In: LIMA, N.T. et al. (Orgs.). Saúde e democracia: história e perspectivas do SUS. Rio de Janeiro: Fiocruz, 2005. p.257-81.

MINAYO, M.C.S. O desafio do conhecimento: pesquisa qualitativa em saúde. São Paulo: Hucitec, 2006.

Hermenêutica-dialética como caminho do pensamento social. In: MINAYO,

M.C.S.; DESLANDES, S.F. (Orgs.). Caminhos do pensamento: epistemologia e método. Rio de Janeiro: Fiocruz, 2002. p.83-107.

MINAYO, M.C.S.; ASSIS, S.G.; SOUZA, E.R. (Orgs.). Avaliação por triangulação de métodos: abordagem de programas sociais. Rio de Janeiro: Fiocruz, 2005.

MORETTI-PIRES, R.O. Complexidade em Saúde da Família e formação do futuro profissional de saúde. Interface - Comunic., Saude, Educ., v.13, n.30, p.153-66, 2009.

MORGAN, D.L. Focus groups as qualitative research. 2.ed. Thousand Oaks: Sage Publications, 1997.

PIRES, M.R.G.M. Politicidade do cuidado e avaliação em saúde: instrumentalizando o resgate da autonomia de sujeitos no âmbito de programas e políticas de saúde. Rev. Bras. Saude Matern. Infant., v.5, supl.1, p.S71-S81, 2005.

SCHRAIBER, L.B. et al. Planejamento, gestão e avaliação em saúde: identificando problemas. Cienc. Saude Colet., v.4, n.2, p.221-42, 1999.

SILVA, I.Z.Q.J.; TRAD, L.A.B. O trabalho em equipe no PSF: investigando a articulação técnica e a interação entre os profissionais. Interface - Comunic., Saude, Educ., v.9, n.16, p.25-38, 2005.

TRAD, L.A.B.; BASTOS, A.C.S. O impacto sócio-cultural do Programa de Saúde da Família (PSF): uma proposta de avaliação. Cad. Saude Publica, v.14, n.2, p.429-35, 1998.

VALENTIM, V.L.; KRUEL, A.J. A importância da confiança interpessoal para a consolidação do Programa de Saúde da Família. Cienc. Saude Colet., v.12, n.3, p.777-88, 2007. 
OLIVEIRA, H.M.; MORETTI-PIRES, R.O.; PARENTE, R.C.P. Las relaciones de poder en equipo de profesionales de Salud de la Familia en un modelo teórico de Hannah Arendt. Interface - Comunic., Saude, Educ., v.15, n.37, p.539-50, abr./jun. 2011.

La Estrategia de Salud de la Familia (ESF) se basa en el trabajo en equipo distanciado del modelo centrado en el médico. Este trabajo propone un modelo teórico para evaluar la relación de poder en el equipo multi-profesional basado en los trabajos de Hannah Arendt. Con el análisis de documentos legales de la ESF y los presupuestos de tales trabajos se establece un modelo teórico para evaluar la ESF. Se aplicaron grupos focales con los equipos de salud y entrevistas individuales en el municipio de Manacaparu, estado de amazonas, Brasil. Los resultados muestran que cada profesional ejecuta su trabajo de forma aislada; la política municipal limita el trabajo colectivo como tiranía en la perspectiva de Arendt, desacreditando a la ESF.

Palabras clave: Poder. Salud de la familia. Equipo de atención al paciente. Grupo focal.

Recebido em 22/01/2010. Aprovado em 23/11/2010 